\section{Invasive fungal infections in endogenous Cushing's syndrome}

\author{
Rafael Selbach Scheffel, ${ }^{\prime}$ \\ José Miguel Dora, ${ }^{1}$ Letícia Schwerz \\ Weinert,' Valério Aquino, ${ }^{2}$ Ana Luiza \\ Maia, 'Luis Henrique Canani, ${ }^{1}$ \\ Luciano Z. Goldani ${ }^{3}$ \\ 'Endocrine Division, ${ }^{2}$ Microbiology Unit \\ of the Clinical Pathology Division, and \\ ${ }^{3}$ Infectious Diseases Unit, Hospital de \\ Clínicas de Porto Alegre, Universidade \\ Federal do Rio Grande do Sul, Porto \\ Alegre, RS, Brazil
}

\begin{abstract}
Cushing's syndrome is a condition characterized by elevated cortisol levels that can result from either augmented endogenous production or exogenous administration of corticosteroids. The predisposition to fungal infections among patients with hypercortisolemia has been noted since Cushing's original description of the disease. We describe here a patient with endogenous Cushing's syndrome secondary to an adrenocortical carcinoma, who developed concomitant disseminated cryptococcosis and candidiasis in the course of his disease.
\end{abstract}

\section{Introduction}

Cushing's syndrome is a condition characterized by supraphysiological cortisol levels that can occur because of either augmented endogenous production or exogenous administration of corticosteroids. ${ }^{1}$ The most common complications of Cushing's syndrome are diabetes, hypertension, obesity, osteoporosis, and a predisposition to mucocutaneous and invasive fungal infections, bacterial infections, reactivation of tuberculosis, and postoperative wound infections. This state is characterized mainly by impaired cell-mediated immunity, augmented by deficient neutrophil and macrophage function. ${ }^{2}$

In this report, we describe a patient with Cushing's syndrome secondary to an adrenocortical carcinoma, who developed concomitant disseminated cryptococcosis and candidiasis in the course of his disease.

\section{Case Report}

A 38-year-old man with a history of hyper- tension was admitted because of hypokalemia and early onset diabetes. He had been attending our outpatient clinic since 2006 and was taking diuretics, beta-blockers, and calcium channel antagonists for his hypertension. In the past two months he presented with an episode of severe hypokalemia with potassium levels of $2.2 \mathrm{mg} / \mathrm{dL}$ and hyperglycemia, which required oral and intravenous potassium replacement and insulin therapy.

A physical examination showed a blood pressure of $170 / 100 \mathrm{mmHg}$, temperature $36.7^{\circ} \mathrm{C}$, with normal cardiac and respiratory rates. The patient presented a typical moon face, truncal obesity, and edema of the legs with proximal muscular weakness. The values of the initial laboratory tests showed a normal blood count and renal function (creatinine 1.0 $\mathrm{mg} / \mathrm{dL})$, hypokalemia $(2.9 \mathrm{mg} / \mathrm{dL})$, and metabolic alkalosis (bicarbonate $45.0 \mathrm{mEq} / \mathrm{L}$ ). The patient was evaluated for Cushing's syndrome. The morning serum cortisol level was 81.7 $\mu \mathrm{g} / \mathrm{dL}$, the midnight serum cortisol level was $89.8 \mu \mathrm{g} / \mathrm{dL}$, and a 24-hour urine cortisol was $8360.59 \mu \mathrm{g} / \mathrm{dL}$ (normal value $<137.0 \mu \mathrm{g} / \mathrm{dL}$ ). Serum ACTH concentration was undetectable $(<10 \mathrm{pg} / \mathrm{mL}$ ). An abdominal CT scan showed a tumor of $12 \mathrm{~cm}$ by $10 \mathrm{~cm}$ with calcifications, an irregular shape, and heterogeneous contrast impregnation in the left adrenal gland. The patient underwent an open adrenalectomy with resection of the left adrenal gland and kidney. The histopathological examination confirmed an adrenocortical carcinoma.

Although hypercortisolism was controlled, in the postoperative period the patient developed septic shock that required hemodynamic and ventilatory support. He was started on broadspectrum antibiotics. In the third day after surgery, the urine culture isolated Cryptococcus neoformans var. neoformans. On the same day, blood cultures grew Candida albicans and Cryptococcus neoformans var. neoformans. Cryptococcus neoformans var. neoformans was also isolated in the culture of the ascites. A lumbar puncture was performed, and there was no evidence of meningitis. In addition to
Correspondence: Luciano Zubaran Goldani, Unidade de Infectologia, Serviço de Medicina Interna, Hospital de Clínicas de Porto Alegre, Rua Ramiro Barcelos 2350, 90035-003 Porto Alegre, RS, Brazil. E-mail: lgoldani@ufrgs.br

Key words: cryptococcosis, candidemia, pneumocystosis, scedosporiosis, histoplasmosis, aspergillosis, Cushing's syndrome, Cushing's disease, hypercortisolemia, fungal infections, mycosis.

Received for publication: 7 September 2009.

Revision received: 28 February 2010.

Accepted for publication: 1 March 2010.

This work is licensed under a Creative Commons Attribution 3.0 License (by-nc 3.0).

(C) Copyright R.Selbach Scheffel et al., 2010

Licensee PAGEPress, Italy

Infectious Disease Reports 2010; 2:e4

doi:10.4081/idr.2010.e4

broad-spectrum antibiotics, the patient was started on amphotericin B and 5'-flucytosine. He developed many surgical complications and recurrent upper gastrointestinal bleeding, and died 90 days after admission because of bacterial peritonitis and refractory septic shock.

\section{Discussion}

Compared with patients with iatrogenic Cushing's syndrome, fewer invasive fungal infections arise in those with endogenous Cushing's syndrome. ${ }^{3}$ ACTH-dependent hypercortisolemia from a functioning pituitary adenoma, and also known as Cushing's disease, makes up approximately $70 \%$ of cases of endogenous hypercortisolemia. In contrast, ACTH-independent hypercortisolemia contributes to approximately $15 \%$ of cases of endogenous Cushing's syndrome. As observed in our patient, the most common cause is an autonomous overproduction of cortisol from an

Table 1. Invasive mycoses described in patients with endogenous Cushing's syndrome.

\begin{tabular}{|c|c|c|}
\hline Fungal infection & Characteristics & References \\
\hline Scedosporiosis & $\begin{array}{c}\text { Osteomyelitis } \\
\text { Arthritis }\end{array}$ & 5 \\
\hline Pneumocystosis & Pneumonia & $6-10$ \\
\hline Aspergillosis & $\begin{array}{l}\text { Invasive pulmonary, } \\
\text { endophthalmitis, } \\
\text { disseminated disease }\end{array}$ & $11-15$ \\
\hline Histoplasmosis & Pulmonary, adrenal & 16,17 \\
\hline Cryptococcosis & $\begin{array}{c}\text { Pulmonary, } \\
\text { meningitis, } \\
\text { disseminated disease }\end{array}$ & $18-26$ \\
\hline Candidiasis & Esophageal, endocarditis & $7,27,28$ \\
\hline
\end{tabular}


adrenal tumor.

The predisposition to fungal infections among patients with hypercortisolemia has been noted since Cushing's original description of the disease. Hypercortisolemia has been shown to impair neutrophil adherence to the endothelium, to decrease degranulation capacity and phagocytic action, to diminish maturation of macrophages, and to down-regulate multiple proinflammatory cytokines. ${ }^{2}$ As shown in Table 1, there are several reports describing invasive fungal infections such as histoplasmosis, aspergillosis, pneumocystosis, cryptococcosis, and candidiasis in patients with endogenous Cushing's syndrome. ${ }^{4-27}$

Our case is unusual as it describes a patient with an endogenous hypercortisolemia that developed concomitant invasive candidiasis and cryptococcosis. In fact, higher levels of endogenous hypercortisolemia increases the risk of infection, and with its anti-inflammatory properties contributes to the subclinical manifestations of these infections. Therefore, invasive fungal infections should be suspected by physicians in patients with endogenous hypercortisolism with early and minimal signs and symptoms of infection unresponsive to broad-spectrum antibiotics. Laboratory tests with a high degree of sensitivity and specificity such as the detection of serum cryptococcal capsular polysaccharide antigen, urinary histoplasmosis antigen in urine, serum galactomannan, serum $\beta$-D glucan, and PCR assays for fungi DNA detection are important diagnostic tools for screening invasive fungal infections in these patients. In addition to specific and aggressive antifungal therapy, pharmacological and surgical treatment for lowering plasma cortisol levels to physiological ranges appears to be a reasonable approach considering that extreme hypercortisolism is an immunological endocrine emergency.

\section{References}

1. Newell-Price J, Bertagna X, Grossman AB, et al. Cushng's syndrome. Lancet 2006; 367:1615-7.

2. Graham BS, Tucker WS. Opportunistic infections in endogenous Cushing's syn- drome. Ann Intern Med 1984;101:334-8.

3. Lionakis MS, Kontayannis DP. Glucorticoids and invasive fungal infection. Lancet 2008;362:1828-38.

4. Fareau GG, Vassilopoulou-Sellin R. Hypercortisolemia and Infection. Infec Dis Clin N Am 2007;21:239-657.

5. Ansari RA, Hindson DA, Stevens DL, et al. Pseudallescheria boydii arthritis and osteomyelitis in a patient with Cushing's disease. South Med J 1987;80:90-2.

6. Keenan N, Dhillo WS, Williams GR, et al. Unexpected shortness of breath in a patient with Cushing's syndrome. Lancet 2006;367:446.

7. Bakker RC, Gallas PR, Romijn JA, et al. Cushing's syndrome complicated by multiple opportunistic infections J Endocrinol Invest 1998;21:329-33.

8. McQuillen DP, Sugar AM. Pneumocystis carinii pneumonia associated with solid ectopic corticotropin-producing tumors. Arch Neurol 1992;49:1012.

9. Fulkerson WJ, Newman JH. Endogenous Cushing's syndrome complicated by Pneumocystis carinii pneumonia. Am Rev Respir Dis 1984;129:188-9.

10. Anthony LB, Greco FA. Pneumocystis carinii pneumonia: a complication of Cushing's syndrome. Ann Intern Med 1981;94:488-9.

11. Joubert M, Reznik Y, Verdon R. Rescue bilateral adrenalectomy in paraneoplastic Cushing's syndrome with invasive Aspergillus fumigatus infection. Am J Med Sci 2007;334:497-8.

12. Kansagara DL, Tetrault J, Hamill C, et al. Fatal factitious Cushing's syndrome and invasive aspergillosis: case report and review of literature. Endocr Pract 2006;12: 651-5.

13. Naylor CD, Shkrum MJ, Edmonds MW, et al. Pulmonary aspergillosis and endophthalmitis: complications of Cushing's syndrome. Can Med Assoc J 1988;138:719-20.

14. Murry PM, Ahern MJ. Disseminated aspergillosis and Cushing's syndrome in a community hospital. Conn Med 1987;51:84-5.

15. Walsh TJ, Mendelsohn G. Invasive aspergillosis complicating Cushing's syndrome. Arch Intern Med 1981;141:1227-8.

16. Kosseifi SG, Nassour DN, Shaikh MA, et al.
Nodular pulmonary histoplasmosis in Cushing's disease: a case report and literature review. Tenn Med 2007;100:44-6.

17. Tan TT, Choy YW, Norizan MA, et al. Adrenal histoplasmosis in Cushing's syndrome with bilateral adrenocortical nodular hyperplasia. Med J Malaysia 1990;45: 154-8.

18. Lacativa PG, Donangelo I, Wagman MB, et al. [Pseudotumoral pulmonary cryptococcosis in association with Cushing's syndrome]. Arq Bras Endocrinol Metabol 2004;48:318-23.

19. Kang CI, Kim SH, Kim HB, et al. Disseminated cryptococcosis in a patient with pituitary Cushing's disease. Korean J Intern Med 2003;18:199-201.

20. Delgrange E, Donckier JE. Cryptococcal meningitis and Cushing's syndrome. Lancet 2000;356:343.

21. Drew PA, Takezawa K. Pulmonary cryptococcosis and pituitary Cushing's disease. Diagn Cytopathol 1998;18:365-7.

22. Hasegawa $\mathrm{Y}$, Kawachi $\mathrm{H}$, Amano $\mathrm{H}$, et al. A case of pulmonary cryptococcosis complicating Cushing's disease]. Nihon Kyobu Shikkan Gakkai Zasshi 1986;24:292-6.

23. Yamamoto N, Negoro M, Yokoe T, et al. [ACTH dependent Cushing's syndrome with an empty sella turcica: report of three cases with emphasis on diagnostic value of selective venous sampling]. No Shinkei Geka 1985;13:1323-8.

24. Kramer M, Corrado ML, Bacci V, et al. Pulmonary cryptococcosis and Cushing's syndrome. Arch Intern Med 1983;143:217980.

25. Ferguson RP. Cryptococcosis and Cushing's syndrome. Ann Intern Med 1977;87:65-6.

26. Dyson BC. Cushing's disease; report of a case associated with carcinoma of the thyroid gland and cryptococcosis. $\mathrm{N}$ Engl $\mathrm{J}$ Med 1959;23;261:169-72.

27. Raju AZ, Mathai D, Singh JP, et al. Candidal oesophagitis in Cushing's syndrome. J Assoc Physicians India 1991;39: 719-21.

28. Giombetti R, Hagstrom JW, Landey S, et al. Cushing's syndrome in infancy. A case complicated by monilial endocarditis. Am J Dis Child 1971;122:264-6. 